\title{
The Multiple LIM Domain-Containing Adaptor Protein Hic-5 Synaptically Colocalizes and Interacts with the Dopamine Transporter
}

\author{
Ana M. Carneiro, ${ }^{1,2}$ Susan L. Ingram, ${ }^{3}$ Jean-Martin Beaulieu, ${ }^{1}$ Ava Sweeney, ${ }^{1}$ Susan G. Amara, ${ }^{3}$ \\ Sheila M. Thomas, ${ }^{4}$ Marc G. Caron, ${ }^{1}$ and Gonzalo E. Torres ${ }^{1}$ \\ ${ }^{1}$ Howard Hughes Medical Institute, Department of Cell Biology, Duke University Medical Center, Durham, North Carolina \\ 27710, 2Department of Biochemistry and Immunology, Universidade Federal de Minas Gerais Belo Horizonte, Brazil, \\ 3Howard Hughes Medical Institute, Vollum Institute, Oregon Health Sciences University, Portland, Oregon 97201, and \\ ${ }^{4}$ Cancer Biology Program, Beth Israel Deaconess Medical Center/Harvard Medical School, Boston, Massachusetts \\ 02215
}

The $\mathrm{Na}^{+} / \mathrm{Cl}^{-}$-dependent dopamine transporter (DAT) is critical in terminating dopaminergic transmission by removing the transmitter away from the synapse. Several lines of evidence suggest that transporter-interacting proteins may play a role in DAT function and regulation. In this report, using the yeast two-hybrid system, we have identified a novel interaction between DAT and the multiple Lin-11, Isl-1, and Mec-3 (LIM) domain-containing adaptor protein Hic-5. This association involves the $\mathrm{N}$-terminal portion of the intracellular tail of DAT and the LIM region of Hic-5. In human embryonic kidney 293 cells, Hic- 5 colocalizes with DAT at polarized sites and reduces DAT uptake activity through a mechanism involving a decrease in the cell-surface levels of the transporter. A fragment of Hic-5 containing the LIM domains is sufficient to bind DAT but lacks the ability to inhibit transporter activity. In addition, the LIM fragment prevents the effect of the full-length Hic-5 on DAT localization and function. In the brain, Hic-5 protein is expressed in the cerebral cortex, hippocampus, hypothalamus, cerebellum, and striatum, suggesting a role for this protein in the nervous system. The association of the endogenous Hic-5 and DAT proteins was confirmed biochemically by coimmunoprecipitation from brain striatal extracts. Moreover, immunostaining of rat midbrain neurons in culture revealed a presynaptic colocalization of Hic-5 and DAT. Because Hic-5 has been shown to interact with several signaling molecules, including the nonreceptor protein tyrosine kinases focal adhesion kinase and Fyn, this raises the possibility that this adaptor protein may link DAT to intracellular signaling pathways.

Key words: dopamine transporter; Hic-5; adaptor; interaction; colocalization; uptake; LIM domain
Dopaminergic neurotransmission plays a major role in the modulation of locomotor activity, neuroendocrine secretion, and emotion (Sealfon and Olanow, 2000). Signaling is initiated with the release of dopamine (DA) from presynaptic terminals followed by activation of presynaptic and postsynaptic DA receptors. A critical step that determines the duration and intensity of DA actions is the reuptake of the neurotransmitter back into the synaptic terminal for subsequent release. This action is achieved by the $\mathrm{Na}^{+} / \mathrm{Cl}^{-}$-dependent plasma membrane dopamine transporter (DAT) (Giros and Caron, 1993). Functional changes in DAT may be involved in the pathogenesis of attention deficit hyperactivity disorder, schizophrenia, and/or neurodegenerative disorders such as Parkinson's disease (Bannon et al., 1998). In addition, drugs of abuse, such as cocaine and amphetamine, exhibit their reinforcing actions at least in part by interacting with DAT (Amara and Sonders, 1998). The importance of DAT in

Received March 29, 2002; revised June 3, 2002; accepted June 5, 2002.

This work was supported by National Institutes of Health Grants NS-19576 (M.G.C.) and DA-14150 (G.E.T.) A.M.C. is a recipient of a fellowship from Companha de Aperfeiçoamento de Pessoal de Nível Superior, Brazil. J.-M.B. is supported by a Human Frontiers Science Program fellowship. S.G.A. and M.G.C. are Investigators of the Howard Hughes Medical Institute. We thank members of the Caron lab for helpful discussions. We also thank Drs. Laura Bohn and Richard T. Premont for reading this manuscript.

Correspondence should be addressed to Dr. Marc G. Caron, Department of Cell Biology, Duke University Medical Center, Room 489, CARL Building, Research Drive, Durham, NC 27710. E-mail: m.caron@cellbio.duke.edu.

Copyright (C) 2002 Society for Neuroscience $0270-6474 / 02 / 227045-10 \$ 15.00 / 0$ controlling DA transmission was demonstrated recently in vivo. Deletion of the DAT gene in mice results in profound behavioral and neurochemical changes, including hyperlocomotor activity, increased dopamine receptor responsiveness, and sensitization to psychostimulants (Giros et al., 1996; Jones et al., 1998; Gainetdinov et al., 1999).

Molecular cloning of genes encoding DAT and other members of the $\mathrm{Na}^{+} / \mathrm{Cl}^{-}$-dependent transporter family, such as the norepinephrine transporter (NET), serotonin transporter (SERT), and glycine and GABA transporters, reveals a highly conserved primary structure (for review, see Masson et al., 1999). Their predicted topology suggests the presence of 12 transmembrane domains with intracellular $\mathrm{N}$ and $\mathrm{C}$ termini. The DAT possesses consensus sequences for phosphorylation by protein kinases (Giros et al., 1991; Kilty et al., 1991; Shimada et al., 1991), suggesting that phosphorylation might play a role in the regulation of DAT function. Indeed, several studies have shown that regulation of kinase activity in striatal synaptosomal preparations and heterologous cell systems affects DAT uptake activity (for review, see Zahniser and Doolen, 2001). This effect is believed to result as a consequence of a rapid redistribution of transporter from the cell membrane (Pristupa et al., 1998; Daniels and Amara, 1999; Melikian and Buckley, 1999; Doolen and Zahniser, 2001). However, neither the identity of the specific kinases involved in the downregulation of DAT nor the direct substrate for phosphorylation has been identified. It has been proposed that transporter- 
interacting proteins might regulate directly or indirectly the kinase-dependent effect on DAT activity (Blakely et al., 1998). This mechanism has been demonstrated for the GABA transporter, where PKC downregulates transporter function by modulating the association of syntaxin with the transporter (Beckman et al., 1998).

Transporter-associated proteins may also play a broader role in transporter stability, location, and/or function. Lee et al. (2001) have shown recently that DAT activity might be affected by a direct interaction between the $\mathrm{C}$ terminus of DAT (CDAT) and $\alpha$-synuclein. DAT function is also regulated by the interaction between DAT and the postsynaptic density-95/discs large/zona occludens-1 (PDZ) domain-containing protein PKC-interacting protein-1 (PICK1) (Torres et al., 2001). Deletion of the PDZbinding site in DAT impairs the targeting of the mutated transporter to neuronal processes in cultured neurons. Thus, the search for DAT-interacting proteins has opened a new and promising opportunity for a better understanding of the mechanisms involved in the regulation of transporter function. Here, we have identified the focal adhesion protein Hic-5 as a DAT-interacting protein. Hic-5 interacts directly with DAT both in vitro and in vivo. In the brain, Hic-5 is expressed in dopaminergic neurons, where it colocalizes and coimmunoprecipitates with DAT. Our findings suggest that Hic-5 may play an important role as an adaptor protein in the regulation of DAT function.

\section{MATERIALS AND METHODS}

Yeast two-hybrid screening. A yeast two-hybrid screening of a human brain library using the intracellular $\mathrm{C}$ terminus of DAT as bait was performed as described previously (Torres et al., 2001). Automated sequencing identified $>20$ clones encoding partial sequences of the open reading frame of Hic-5. Fragments expressing the $\mathrm{C}$ termini of DAT, NET (residues 575-617), or SERT (residues 594-630) or the $\mathrm{N}$ terminus of DAT (NDAT) (residues 1-60) were subcloned into pAS2.1 and transformed in pG694a yeast cells with a Hic-5 clone fused to pGAD10 using the LiAc method. Transformation efficiency was verified by growing transformed yeast cells in leucine- and tryptophan-deficient medium, whereas specific interactions between each fragment and Hic-5 were verified by the growth of yeast colonies in leucine-, tryptophan-, and adenine-free medium after $2-5 \mathrm{~d}$ of incubation at $30^{\circ} \mathrm{C}$.

Cell culture and transfections. Human embryonic kidney 293 (HEK293) cells were maintained in MEM supplemented with 10\% FBS and 50 $\mathrm{U} / \mathrm{ml}$ gentamicin (Invitrogen, Grand Island, NJ). Cells were transfected using the $\mathrm{Ca}_{2} \mathrm{PO}_{4}$ precipitation method with $10 \mu \mathrm{g}$ of total DNA. After $16-20 \mathrm{hr}$ at $37^{\circ} \mathrm{C}$ with the $\mathrm{Ca}_{2} \mathrm{PO}_{4}$-DNA mixture, transfected cells were incubated with fresh MEM and allowed to grow for an additional $48 \mathrm{hr}$.

Western blot analysis. Protein samples were prepared by incubation of transfected HEK293 cells with radioimmunoprecipitation assay (RIPA) buffer (in mM): 100 Tris, $150 \mathrm{NaCl}, 1$ EDTA, $1 \%$ Triton $\mathrm{X}-100,0.1 \%$ SDS, and $1 \%$ deoxycholic acid, $\mathrm{pH} 7.4$, for $30 \mathrm{~min}$ at $4^{\circ} \mathrm{C}$ followed by centrifugation at $14,000 \mathrm{rpm}$ for $10 \mathrm{~min}$. Alternatively, C57BL/6 mice were killed, and brain tissues were dissected and homogenized in RIPA buffer. Samples were analyzed on $10 \%$ polyacrylamide gels and electroblotted to nitrocellulose membranes using the Novex precast gel (Wadsworth, $\mathrm{OH}$ ) and transfer system (Invitrogen, Carlsbad, CA). Hic-5 was detected using a mouse monoclonal antibody raised against the prolinerich region of Hic-5 (BD Transduction Laboratories, San Diego, CA) followed by a secondary HRP-linked anti-mouse antibody (Amersham Biosciences, Uppsala, Sweden). DAT was detected using a rat monoclonal antibody raised against the N-terminal domain of human DAT (Chemicon International Inc., Temecula, CA) and a secondary goat HRP-conjugated anti-rat antibody (Jackson ImmunoResearch, West Grove, PA). Membranes were blocked in 5\% milk in TBS-T (in mM): 10 Tris, $\mathrm{pH} \mathrm{7.4,} 100 \mathrm{NaCl}$, and $0.05 \%$ Tween 20, for $30 \mathrm{~min}$ at room temperature and incubated with the appropriate primary antibody. The primary antibodies were used at a 1:1000 dilution for $1 \mathrm{hr}$ at room temperature for samples from HEK293 cells or at 1:500 for $18-20 \mathrm{hr}$ at $4^{\circ} \mathrm{C}$ for samples from brain extracts. The membranes were then washed three times with TBS-T, followed by incubation with secondary antibod- ies for $1 \mathrm{hr}$. Immunoreactive bands were detected with the ECL system (Amersham Biosciences).

Glutathione S-transferase fusion protein precipitations. Glutathione $S$-transferase (GST) constructs containing the entire C-terminal domain of DAT (residues 575-620) or NET (residues 575-617) were amplified by PCR using Taq polymerase (Fisher, Pittsburgh, PA) containing $10 \%$ of Vent polymerase (New England Biolabs Inc., Beverly, MA). Small 10 aa fragments from the C-terminal region of DAT were generated by annealing complementary designed primers (Sigma Genosys, The Woodlands, TX). These constructs were fused in frame into the GST fusion vector PGEX-4T-1 (Amersham Biosciences, Piscataway, NJ) and verified by automated sequencing. GST-fused fragments were expressed in BLXBlue bacterial cells and isolated with glutathione-agarose beads (Amersham Biosciences). Aliquots containing GST fusion fragments were then incubated with either $500 \mu \mathrm{g}$ of protein lysates from transfected HEK293 cells or $1 \mathrm{mg}$ of brain lysate. Mixtures were incubated with GST beads (Amersham Biosciences), washed three times with RIPA buffer, and prepared for Western blotting as described previously.

Immunoprecipitations. Lysates from transfected HEK293 cells or mouse tissue were prepared using RIPA buffer. Immunoprecipitations from HEK293 cell lysates were performed using either anti-hemagglutinin (HA) or anti-myc monoclonal antibodies (Roche Diagnostics Corp., Indianapolis, IN). Aliquots of the cleared lysates (500 $\mu \mathrm{g}$ of protein) were incubated with $15 \mu \mathrm{g}$ of the appropriate antibody at $4^{\circ} \mathrm{C}$ for $16-18 \mathrm{hr}$. Protein A Sepharose beads (Amersham Biosciences) were then added and incubated for $2 \mathrm{hr}$ at $4^{\circ} \mathrm{C}$. The beads were washed three times with RIPA buffer and prepared for Western blotting. Immunoprecipitations using brain lysates were performed using $1 \mathrm{mg}$ of total protein and $1 \mu \mathrm{g}$ of the anti-Hic- 5 antibody. Samples were analyzed by Western blotting as described above.

Transport measurements. Uptake experiments in transfected HEK293 cells were performed as described previously (Giros et al., 1994). Briefly, $48 \mathrm{hr}$ after transfections, cells were incubated at $37^{\circ} \mathrm{C}$ for $5 \mathrm{~min}$ in $250 \mu \mathrm{l}$ of uptake buffer (in mM): 5 Tris base, 7.5 HEPES, $120 \mathrm{NaCl}, 5.4 \mathrm{KCl}, 1.2$ $\mathrm{CaCl}_{2}, 1.2 \mathrm{MgSO}_{4}, 1$ ascorbic acid, and 5 glucose, $\mathrm{pH} 7.4$, containing 20 $\mathrm{nM}\left[{ }^{3} \mathrm{H}\right] \mathrm{DA}(31.6 \mathrm{Ci} / \mathrm{mmol})$ and increasing concentrations of cold DA, ranging from 100 to $30 \mu \mathrm{M}$. Cells were then washed with $500 \mu \mathrm{l}$ of $\mathrm{NaCl}$-free uptake buffer and solubilized for $1 \mathrm{hr}$ in $400 \mu \mathrm{l}$ of $1 \%$ SDS. The amount of radioactivity incorporated into the cells was measured by scintillation counting. Data are presented as mean \pm SEM. Statistical significance was determined by unpaired Student's $t$ test with a significance criterion of $p<0.05$.

Cell-surface biotinylation. Transfected HEK293 cells were washed with PBS and incubated for $40 \mathrm{~min}$ at $4^{\circ} \mathrm{C}$ with $1 \mathrm{mg} / \mathrm{ml}$ sulfosuccinimidyl 2-(biotinamido)ethyl-1, 3-dithiopropionate (sulfo-NHS-SS-biotin; Pierce, Rockford, IL) in (in $\mathrm{mm}$ ): $150 \mathrm{NaCl}, 2 \mathrm{CaCl}_{2}$, and 10 triethanolamine, $\mathrm{pH}$ 7.8 , followed by incubation with $0.1 \mathrm{M}$ glycine in PBS for $10 \mathrm{~min}$. After two washes with PBS, cells were lysed in $1 \mathrm{ml}$ of RIPA buffer for $1 \mathrm{hr}$ at $4^{\circ} \mathrm{C}$, scraped, and centrifuged for $10 \mathrm{~min}$ at $4^{\circ} \mathrm{C}$. Two aliquots of the supernatant were collected; $5 \mu \mathrm{l}$ were used for total protein normalization in Western blots, and $500 \mu \mathrm{l}$ were incubated with $25 \mu \mathrm{l}$ of $50 \%$ avidin beads (Pierce) at $4^{\circ} \mathrm{C}$ for $16-18 \mathrm{hr}$. The beads were washed three times with PBS and prepared for Western blotting using the anti-DAT antibody.

Immunocytochemistry and confocal microscopy. Transiently transfected HEK293 cells were plated on glass coverslips and grown for $48 \mathrm{hr}$ at $37^{\circ} \mathrm{C}$. Cells were washed with PBS and fixed with $4 \%$ paraformaldehyde for $10 \mathrm{~min}$ at $4^{\circ} \mathrm{C}$. After three washes with PBS, the cells were blocked in PBS solution containing 5\% goat serum, 1\% BSA, and $0.05 \%$ Triton $\mathrm{X}-100$; Sigma-Aldrich Co., Irvine, CA) for $1 \mathrm{hr}$ at room temperature. Coverslips were incubated for $1 \mathrm{hr}$ with a rat anti-DAT antibody and/or a rabbit anti-Hic-5 antibody (Matsuya et al., 1998), both at a dilution of 1:1000. After three washes with PBS, cells were incubated with FITCtagged anti-rabbit or Texas Red-conjugated anti-rat secondary antibodies (Jackson ImmunoResearch), both at a 1:200 dilution for $1 \mathrm{hr}$. Coverslips were then washed in PBS and mounted onto glass slides with Vectashield mounting medium (Vector Laboratories, Inc., Burlingame, CA). Neuronal cultures were prepared as described previously (Rayport et al., 1992). Briefly, Sprague Dawley rat pups (2-4 d of age) were anesthetized by intraperitoneal injection of ketamine $\mathrm{HCl}$ (3 mg/pup). Ventral midbrains were dissected and incubated in a dissociation medium under constant oxygenation for $2 \mathrm{hr}$, followed by trituration with a fire-polished Pasteur pipette in glial medium (MEM, $10 \%$ FBS, $0.45 \%$ D-glucose, $5 \mathrm{pg} / \mathrm{ml}$ insulin, $0.5 \mathrm{~mm}$ glutamine, $100 \mathrm{U} / \mathrm{ml}$ penicillin, and $100 \mu \mathrm{g} / \mathrm{ml}$ streptomycin). Dissociated cells were pelleted by centrifugation, plated on 24 well plates containing glass coverslips, and allowed to grow for 5-7 d. 
Cells were then fixed in $4 \%$ paraformaldehyde for 10 min, washed in PBS, and incubated in blocking solution (4\% goat serum, $1 \%$ BSA, and $0.2 \%$ Triton X-100 in PBS) for 30 min followed by incubation with primary antibodies at a 1:500 dilution in $0.25 \%$ BSA and $0.2 \%$ Triton $\mathrm{X}-100$ in PBS for $16-18 \mathrm{hr}$ at $4^{\circ} \mathrm{C}$. Secondary antibodies were added at a 1:200 dilution and incubated for $2 \mathrm{hr}$ at room temperature. Coverslips were mounted on glass slides, and the samples were visualized using a laser scanning confocal microscope (Zeiss, Thornwood, NY) at $498 \mathrm{~nm}$ for FITC and $585 \mathrm{~nm}$ for Texas Red.

\section{RESULTS}

\section{In vitro interaction between DAT and Hic-5}

To search for DAT-interacting proteins, we used the yeast twohybrid system to screen a human brain cDNA library using the intracellular C-terminal domain of DAT as bait. From $\sim 20$ million transformants screened, $\geq 20$ positive clones were found to encode partial sequences of the open reading frame of Hic-5, a 461 aa protein highly homologous to the focal adhesion protein paxillin. Hic-5 was first identified as a TGF- $\beta$-inducible gene and proposed initially to function as a transcription factor because of the presence of four double zinc-finger LIM domains located in the C-terminal half of the protein (Shibanuma et al., 1994, 1997). Although the function of Hic-5 is still not fully understood, its high homology with paxillin, as well as its presence in focal adhesion structures, suggests the involvement of Hic-5 as an adaptor protein regulating focal adhesion dynamics (Thomas et al., 1999).

We examined the specificity of the DAT and Hic-5 interaction by testing in the yeast two-hybrid system the ability of Hic-5 to bind the $\mathrm{C}$ termini of the monoamine transporters NET and SERT. As shown in Figure $1 A$, Hic-5 also interacts with the intracellular tails of NET and SERT in yeast, although the interaction with SERT is weaker when compared with that obtained with either DAT or NET. To limit the possibility of a falsepositive interaction, we used the intracellular $\mathrm{N}$-terminal domain of DAT as a control. No interaction between the $\mathrm{N}$ terminus of DAT and Hic-5 was detected in yeast (Fig. $1 A$ ).

To confirm the interaction of the $\mathrm{C}$ terminus of DAT with Hic-5, we performed a GST fusion protein precipitation assay using the complete $\mathrm{C}$ terminus of DAT fused to GST (GSTCDAT) (Fig. 1B). Results from precipitation experiments with GST beads using mouse whole-brain lysates demonstrate the association between GST-CDAT and Hic-5 under conditions in which GST alone was not able to associate with Hic-5. In addition, the $\mathrm{C}$ terminus of NET fused to GST (GST-CNET) also interacts with Hic-5 from brain lysates (Fig. $1 B$ ). Thus, these findings demonstrate a physical association between the tail of monoamine transporters and the endogenous Hic-5.

\section{Interaction between the full-length Hic-5 and DAT in mammalian cells}

We subsequently examined whether the full-length DAT interacts with Hic-5 in mammalian cells by coexpressing the HA-tagged human DAT and the myc-tagged Hic-5 in HEK293 cells. Neither Hic-5 nor DAT were detected in mock-transfected cells as revealed with the anti-Hic-5 and the anti-DAT antibodies, respectively (Fig. $2 A, B$ ). Immunoprecipitation with the anti-myc antibody results in the coprecipitation of HA-DAT only when both proteins were coexpressed in HEK293 cells (Fig. 2A). In addition, immunoprecipitation of HA-DAT also results in the coprecipitation of Hic-5-myc when both tagged proteins are coexpressed in HEK293 cells (Fig. 2B), demonstrating that the association between the full-length DAT and Hic-5 proteins is independent of which protein is first pulled down.
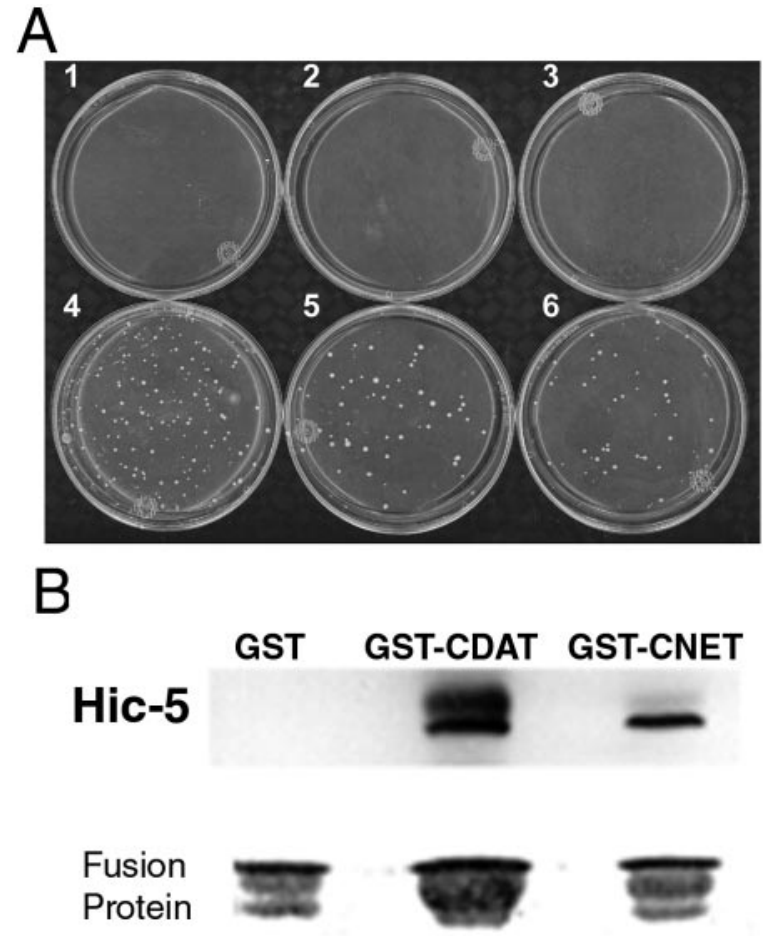

Figure 1. The C-terminal domain of DAT interacts with Hic-5 in vitro. A, Interaction between the tail of monoamine transporters and Hic-5. pG694a yeast cells were transformed with pAS2.1 and pGAD10/Hic-5 (1), pAS2.1/CDAT and pGAD10 (2), pAS2.1/NDAT and pGAD10/ Hic-5 (3), pAS2.1/CDAT and pGAD10/Hic-5 (4), pAS2.1/CNET and pGAD10/Hic-5 (5), or pAS2.1/CSERT and pGAD10/Hic-5 (6). Positive transformant yeast cells were selected in media lacking tryptophan, leucine, and adenine. CDAT, CNET, and CSERT represent the C terminus of DAT, NET, and SERT, respectively, whereas NDAT represents the $\mathrm{N}$ terminus of DAT. B, GST fusion protein precipitation assay using the complete $\mathrm{C}$ terminus of DAT or NET fused to GST. Aliquots containing GST fusion fragments were incubated with $1 \mathrm{mg}$ of mouse whole-brain lysate and analyzed by Western blot using a polyclonal anti-Hic-5 antibody.

\section{Mapping the interacting domains of the DAT and Hic-5 interaction}

Hic-5 contains multiple domains that have been shown to be responsible for protein-protein interactions. The N-terminal half contains four leucine-rich domains (LD) that mediate the interaction between Hic-5 and several focal adhesion proteins, including the focal adhesion kinase (FAK) (Fujita et al., 1998) and cell adhesion kinase $\beta(\mathrm{CAK} \beta) /$ Pyk2 (Matsuya et al., 1998; Osada et al., 2001). In contrast, the C-terminal half contains four LIM domains, each one consisting of two zinc-finger motifs. These domains are responsible for the interaction between Hic-5 and protein tyrosine phosphatase-proline serine threonine (PTPPEST) (Nishiya et al., 1999) and the glucocorticoid receptor (Yang et al., 2000). To determine which region in Hic-5 mediates the interaction with DAT, we used two myc-tagged Hic-5 fragments corresponding to the LD domain-containing $\mathrm{N}$-terminal half (residues 1-210; NH-myc) or the multiple LIM domaincontaining C-terminal half (residues 211-461; COOH-myc). These constructs were expressed with DAT in HEK293 cells and assayed for protein-protein interaction by coimmunoprecipitation experiments using the anti-myc antibody. In cells coexpressing $\mathrm{COOH}$-myc and DAT, immunoprecipitation with the antimyc antibody resulted in coprecipitation of DAT. COOH-myc 
A IP: anti-HA

IB: anti-Hic-5

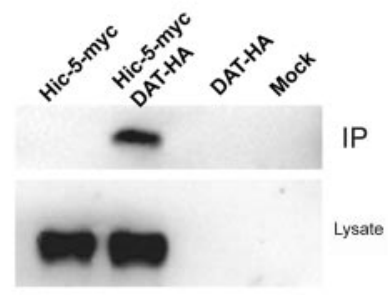

B IP: anti-c-myc

IB: anti-DAT

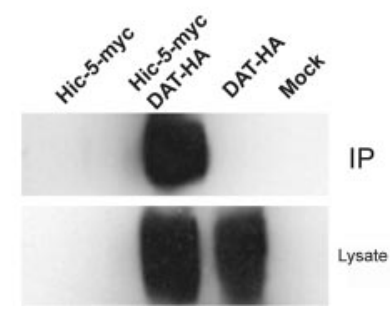

Figure 2. The full-length DAT interacts with Hic-5 in HEK293 cells. HEK293 cells were transfected with the HA-tagged human DAT and the myc-tagged mouse Hic-5 individually or in combination. $A$, Immunoprecipitations $(I P)$ with the anti-HA antibody and Western blot detection $(I B)$ with a polyclonal anti-Hic-5 antibody. Hic-5-myc is immunoprecipitated with the anti-HA antibody only when coexpressed with DAT-HA. $B$, Immunoprecipitations using the anti-myc antibody and Western blot detection with the rat anti-DAT antibody. DAT-HA is immunoprecipitated with the anti-myc antibody only when it is coexpressed with Hic-5-myc.

was as efficient as the full-length myc-tagged Hic-5 at coprecipitating DAT (Fig. 3A). In contrast, no association was detected when DAT was coexpressed with $\mathrm{NH}$-myc, indicating that the multiple LIM domain-containing $\mathrm{C}$ terminus of Hic-5 mediates the interaction between Hic-5 and DAT.

Next, we mapped the residues within the intracellular tail of DAT involved in the interaction with Hic-5. Six 10 aa GST-fused fragments covering the last 60 residues from the $\mathrm{C}$ terminus of DAT (Fig. 3B) were generated and tested for their ability to interact with Hic-5 in precipitation experiments. The strongest interaction was observed between Hic-5 and fragment 2 (residues 571-580), whereas a much weaker interaction was observed when using fragment 1 (residues 561-570) or fragment 3 (residues 581-590) (Fig. 3B). No interaction was detected when any of the three fragments corresponding to the last 30 aa of DAT were used in the GST precipitation with GST fusion proteins. Together, these results indicate that the interaction between DAT and Hic-5 is mediated by the multiple LIM domain-containing half of Hic-5 and the membrane-proximal portion of the intracellular tail of DAT.

\section{Effect of Hic-5 overexpression on DAT function and localization}

Having demonstrated a physical interaction between DAT and Hic-5, we then investigated the effect of Hic-5 overexpression on DAT uptake activity in transfected HEK293 cells. In cells coexpressing Hic-5 and DAT, the total DA uptake activity was decreased by an average of $30 \%$ when compared with cells expressing DAT alone $\left(V_{\max }=12.4 \pm 1.1 \mathrm{pmol} \cdot \mathrm{min}^{-1} \cdot\right.$ well $^{-1}$ in cells expressing DAT vs $8.9 \pm 0.6 \mathrm{pmol} \cdot \mathrm{min}^{-1} \cdot$ well $^{-1}$ in cells expressing DAT and Hic-5) (Fig. 4A). No significant changes in the affinity of DA for the transporter were observed $\left(K_{\mathrm{m}}=1.2 \pm 0.24\right.$ $\mu \mathrm{M}$ in cells expressing DAT vs $1.4 \pm 0.31 \mu \mathrm{M}$ in cells expressing DAT and Hic-5). These data suggest that the reduced DAT activity in the presence of Hic-5 is not attributable to changes in the intrinsic properties of DAT but rather to a decrease in the number of transporters expressed at the plasma membrane. To test this hypothesis, we performed biotinylation experiments in HEK293 cells using sulfo-NHS-SS-biotin. This compound, which binds to lysine and arginine residues in proteins, is cell impermeant and can be used to label cell-surface proteins. Cells transfected with either DAT alone or DAT and Hic-5 were incubated
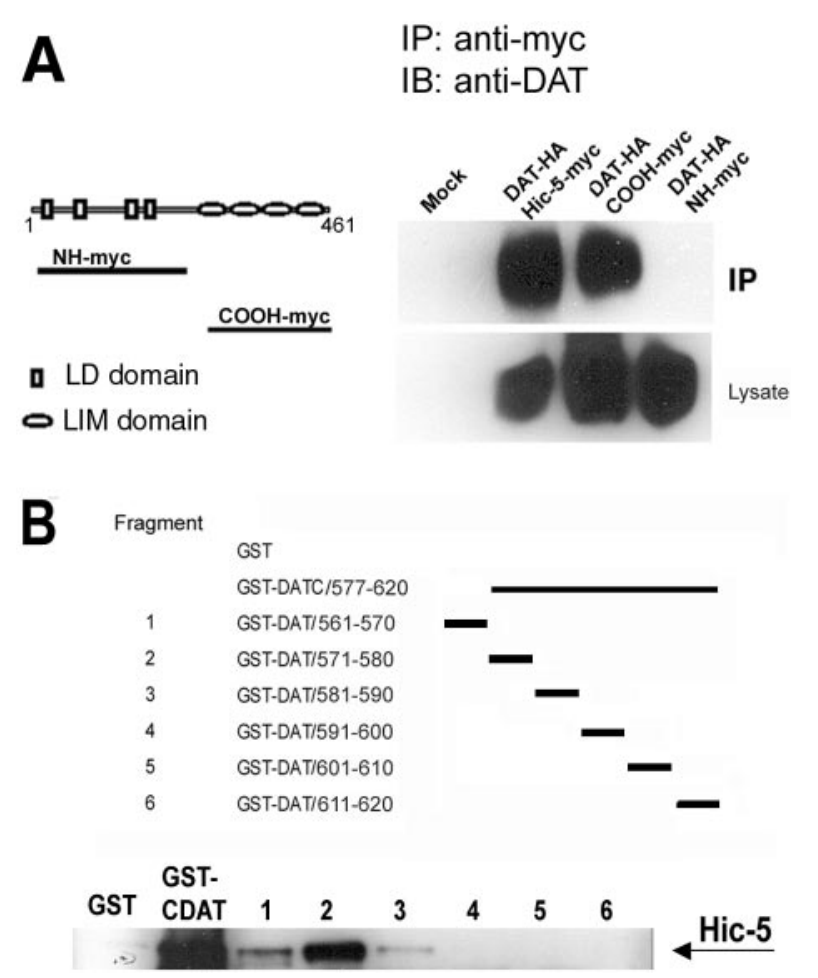

Figure 3. Domains involved in the interaction between Hic-5 and DAT. $A$, The multiple LIM domain-containing $\mathrm{C}$ terminus of Hic-5 mediates the interaction with DAT. Left panel, Schematic diagram of the myctagged multiple LD motif-containing $\mathrm{N}$ terminus (NH-myc) and myctagged multiple LIM domain-containing $\mathrm{C}$ terminus of Hic-5 (COOHmyc). Right panel, Protein lysates of cells transfected with the indicated constructs were immunoprecipitated with the anti-myc antibody. DAT was coprecipitated only when coexpressed with the C terminus of Hic-5. B, Hic-5 binds to amino acids 571-580 of DAT. Top panel, Schematic diagram of the fragments containing 10 aa pieces of the last 60 residues of the $\mathrm{C}$ terminus of DAT as GST fusion proteins. DATC represents the $\mathrm{C}$ terminus of DAT. Bottom panel, GST-fused fragments were incubated with lysates from HEK293 cells transfected with Hic-5, precipitated with GST beads, and analyzed by Western blot with a polyclonal anti-Hic-5 antibody. $I B$, Immunoblotting; $I P$, immunoprecipitation.

with sulfo-NHS-SS-biotin, followed by isolation of labeled proteins with avidin beads and analysis by Western blot using the anti-DAT antibody. As shown in Figure $4 B, C$, the levels of DAT at the cell membrane were decreased by an average of $30 \%$ when coexpressed with Hic-5, under conditions in which the total levels of transporter protein remained unchanged. Thus, these results indicate that the decrease in DAT uptake activity by Hic- 5 overexpression in HEK293 cells results as a consequence of a decrease in cell-surface levels of DAT. As a control, we used the unrelated $\beta 2$ adrenergic receptor. Overexpression of this protein with DAT did not result in inhibition of transporter function, indicating that the reduced activity seen with Hic-5 is not a consequence of a general effect of protein overexpression in DAT function (data not shown).

We subsequently examined the distribution pattern of DAT and Hic-5 when expressed alone or in combination in HEK293 cells. In cells expressing DAT alone, the transporter is distributed throughout the plasma membrane when visualized by immunostaining with the anti-DAT antibody (Fig. 5, top panel). In contrast, Hic-5 showed a unique distribution pattern characterized as focalized immunostaining concentrated on one side of the cell (Fig. 5, middle panel). No cross-reactivity was observed between 

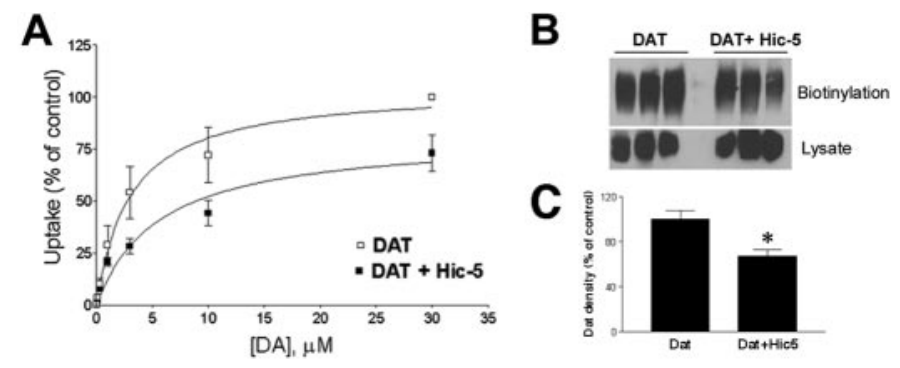

Figure 4. Hic-5 overexpression downregulates DAT uptake activity by decreasing the cell-surface levels of the transporter. $A,\left[{ }^{3} \mathrm{H}\right] \mathrm{DA}$ uptake activity in cells transfected with DAT alone $(\square)$ or in combination with Hic-5 (ם). Each point corresponds to the mean \pm SEM of three independent experiments. $B$, Biotinylation experiments in cells transfected with DAT alone or in combination with Hic-5. Transfected HEK293 cells were incubated with sulfo-NHS-SS-biotin, and labeled proteins were analyzed by Western blot using the rat anti-DAT antibody. Results are representative of three independent experiments. $C$, Averaged quantitation of Hic-5 overexpression on DAT surface density. Immunoblots from five separate biotinylation experiments were scanned densitometrically, and mean values were plotted \pm SEM. Data are expressed as a percentage of control. The asterisk indicates a statistically significant reduction in biotinylated DAT protein $(p<0.05$; Student's $t$ test).
$\alpha$-DAT
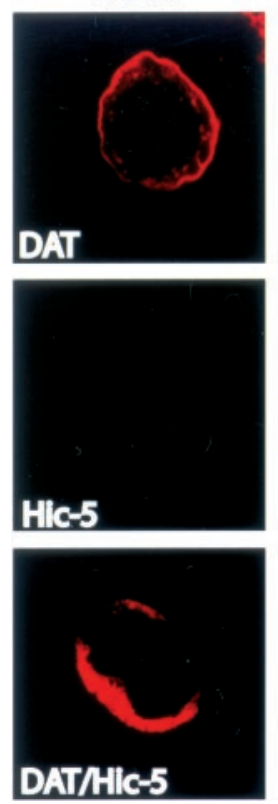

$\alpha-\mathrm{Hic}-5$
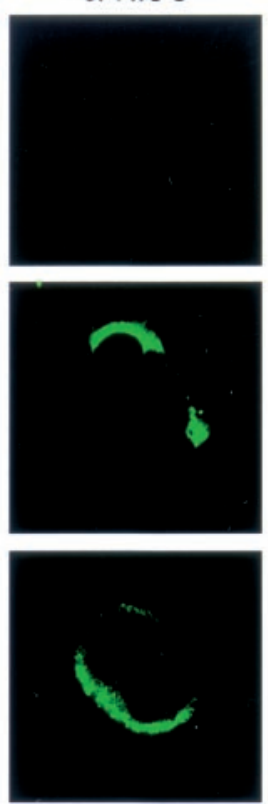

overlay
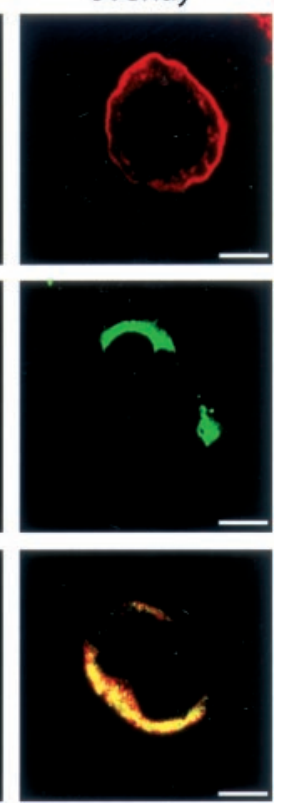

Figure 5. Hic-5 colocalizes with DAT in HEK293 cells. The distribution pattern of DAT and Hic-5 when expressed individually or in combination in HEK cells is shown. Immunostaining was performed using the rat anti-DAT or the rabbit anti-Hic-5 antibodies and secondary antibodies: Texas Red anti-rat and FITC-conjugated anti-rabbit antibodies. Note that there is no increase in the intensity of the DAT signal in the presence of Hic-5. Individual cells displayed are representative of the entire population of cells from five independent experiments. Scale bars, $25 \mu \mathrm{m}$.

the rat anti-DAT and the rabbit anti-Hic-5 antibodies. In cells coexpressing DAT and Hic-5, the distribution pattern of DAT changed dramatically and resembled that of Hic-5 (Fig. 5, bottom panel). The strongest DAT signal was found on one side of the cell, where it colocalized with Hic-5.

To examine the specificity of the Hic-5 and DAT interaction, we tested whether a fragment containing the multiple LIM domain of Hic-5 (COOH-myc) was able to compete with Hic-5 for
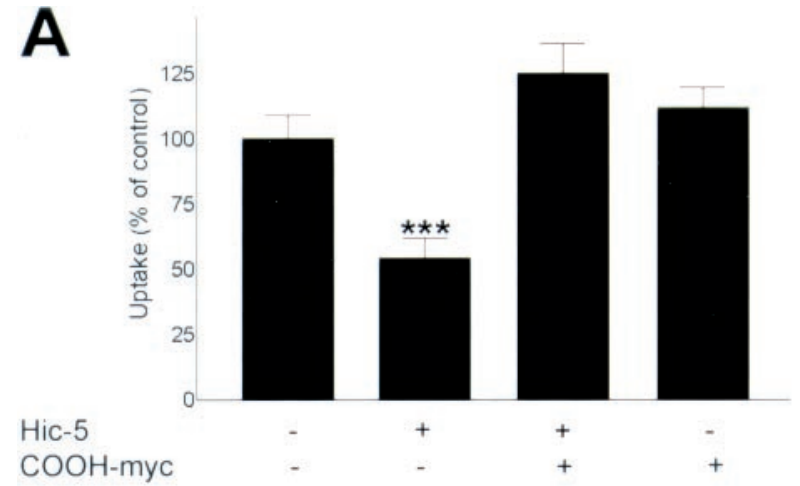

$\mathrm{Hic}-5$ $\mathrm{COOH}-\mathrm{myc}$

8

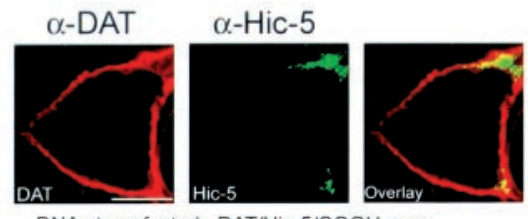

Figure 6. Dominant-negative effect of the multiple LIM domaincontaining $\mathrm{C}$-terminal half of Hic-5. $A,\left[{ }^{3} \mathrm{H}\right] \mathrm{DA}$ uptake activity in cells transfected with the indicated constructs. The $\mathrm{COOH}-m y c$ fragment blocks the downregulation of DAT uptake activity by Hic-5, whereas no effect on uptake activity was observed when the $\mathrm{COOH}$-myc was coexpressed with DAT $(* * * p \leq 0.001)$. $B$, The expression of COOH-myc abolishes the colocalization of DAT and Hic-5 in HEK293 cells. Immunostaining was performed as described using the rat anti-DAT antibody and the polyclonal anti-Hic-5 antibody. Note that the Hic-5 antibody does not detect the Hic-5 fragment containing the LIM region. Scale bar, $25 \mu \mathrm{m}$.

the interacting site in DAT. As stated before and shown in Figure $6 A$, overexpression of Hic-5 reduces DAT activity in HEK293 cells. However, cotransfection of the LIM region of Hic-5 along with Hic-5 and DAT blocked the reduction of DA uptake induced by Hic-5 alone. The LIM region of Hic-5 alone was not able to inhibit DAT activity (Fig. 6A). Next, we examined the distribution of Hic-5 and DAT now in the presence of the LIM fragment. Because the Hic-5 polyclonal antibody was raised against an $\mathrm{N}$-terminal epitope of this protein, it does not detect the Hic-5 fragment containing the LIM domains. As shown in Figure $6 B$, in cells transfected with Hic-5, DAT, and the LIM fragment, the distribution of Hic-5 and DAT was similar to that observed in cells transfected with the individual constructs. Together, these results suggest that the LIM fragment prevents the effect of the full-length Hic-5 on DAT function by disrupting the association of DAT with the full-length Hic-5 in cells.

\section{Hic-5 colocalizes with DAT in dopaminergic neurons in culture}

To establish the physiological significance of our findings in vivo, we examined the cellular distribution of Hic-5 and DAT in cultured rat midbrain neurons by immunocytochemistry using the polyclonal anti-Hic-5 antibody. In non-neuronal cells from these cultures, Hic-5 immunoreactivity was primarily detected in focal structures recognized as elongated tips (Fig. 7A,D, left panel). However, in neurons, Hic-5 showed punctate staining that was concentrated at the cell body and along the neuronal processes (Fig. $7 B$ ). Interestingly, specific staining to Hic-5 was consistently seen at the tip of the neuronal projections (Fig. $7 D$, right panel), consistent with the polarized expression of this protein observed in non-neuronal cells. To confirm the specificity of the staining 

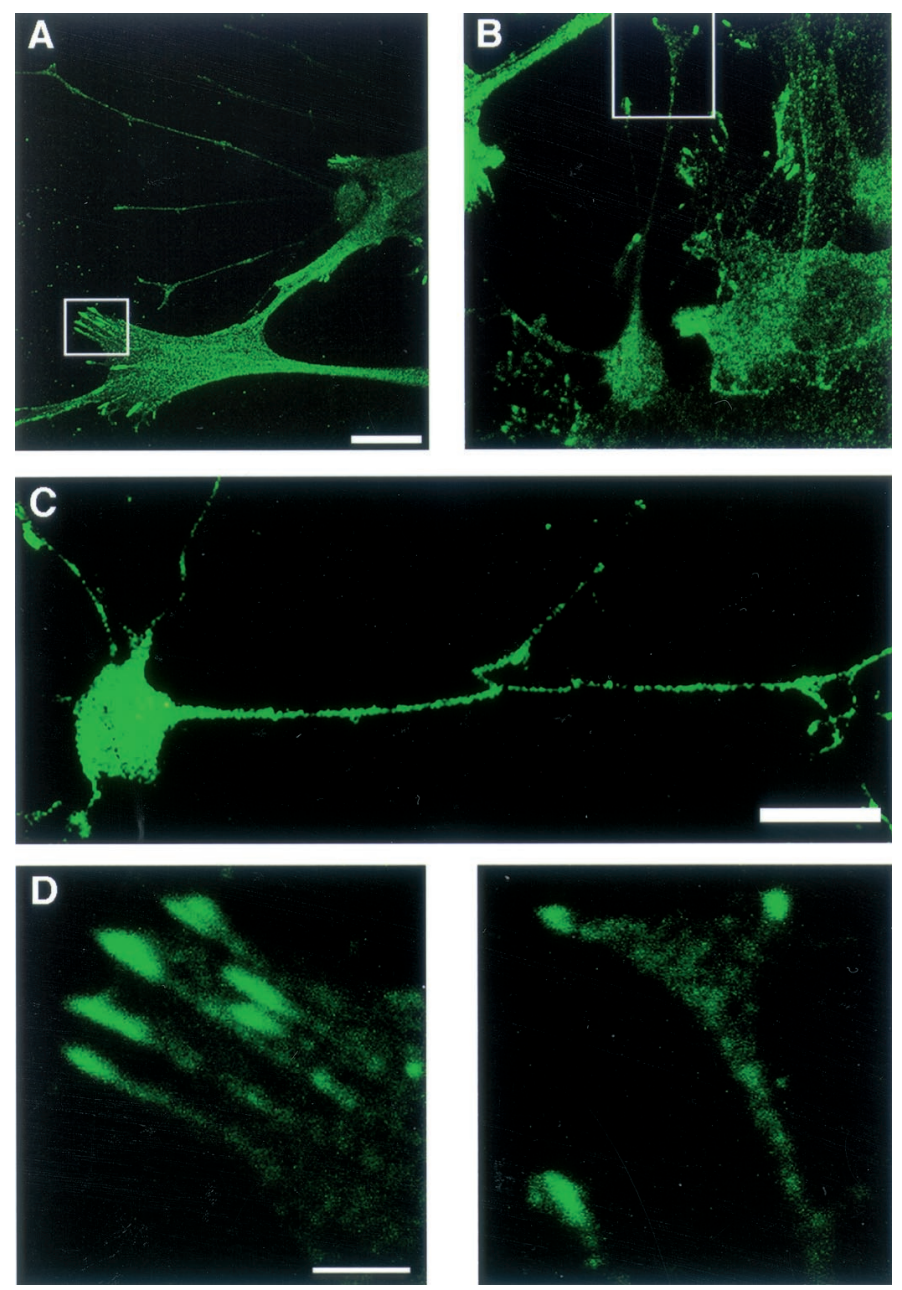

Figure 7. Hic-5 is expressed in neuronal and non-neuronal cells from rat midbrain cultures. Dissociated cells from rat ventral midbrains were plated on glass coverslips and immunostained with the polyclonal antiHic-5 antibody. $A$, Primary non-neuronal cells show prominent immunoreactivity at focal structures; the boxed area in $A$ is magnified as the left panel in $D . B, D$, right panel, Hic-5 antibody showed a punctated immunoreactivity in neuronal cells; the boxed area in $B$ is magnified as the right panel in D.C, A monoclonal anti-Hic-5 antibody showed a similar staining pattern in neurons. Scale bars: $A, 15 \mu \mathrm{m} ; C, 25 \mu \mathrm{m} ; D, 2.5 \mu \mathrm{m}$.

pattern observed with the polyclonal antibody, a second antibody was used for immunocytochemistry. As shown in Figure $7 C$, a similar labeling pattern was observed in neurons when using a Hic-5 monoclonal antibody (Fig. 7C).

Hic-5 has been shown to interact with FAK in mouse fibroblasts and platelets (Fujita et al., 1998; Hagmann et al., 1998; Thomas et al., 1999; Nishiya et al., 2001). FAK is a nonreceptor tyrosine kinase responsible for the recruitment of various signaling proteins to focal adhesion structures (Parsons et al., 2000). We then examined whether FAK was present in cultured midbrain neurons using a specific monoclonal FAK antibody. FAK immunoreactivity showed a punctated distribution in cell bodies and tips of neurites, where it colocalized with Hic-5 (Fig. 8A). Next, we examined the subcellular localization of Hic-5 in double staining experiments using a syntaxin antibody marker to label presynaptic structures. Syntaxin is a plasma membrane protein implicated in neurotransmitter release and is localized at synaptic junctions of axonal membranes (Hepp and Langley, 2001). Hic-5 staining along neurites colocalized extensively with syntaxin, indicating that Hic-5 immunoreactivity is present at presynaptic terminals (Fig. 8B). Finally, we examined whether Hic-5 and DAT colocalize in dopaminergic neurons. As shown in Figure 9 (top panel), DAT immunoreactivity was observed as clusters along the neuronal projections. These DAT containing clusterlike structures in mouse midbrain neurons in culture have been described previously (Torres et al., 2001). Only a small fraction of the total neurons in culture were labeled with the DAT antibody, whereas Hic-5 immunostaining was observed in a larger population of neurons and non-neuronal cells. Double staining with DAT and Hic-5 antibodies revealed extensive overlap of these proteins along neuronal processes, demonstrating that Hic-5 is expressed in dopamine neurons and colocalizes with DAT. Because Hic-5 was shown to interact with FAK, we examined whether this kinase was also expressed in dopamine neurons. As shown in Figure 9 (bottom panels), FAK immunoreactivity was detected in DAT-positive neurons.

\section{Interaction between DAT and Hic-5 in brain}

Jia et al. (2001) recently reported the only evidence available showing the distribution of Hic-5 protein in mouse tissues. By immunoblot analysis, Hic-5 was shown to be highly expressed in the large intestine, lung, spleen, testis, and uterus; moderately expressed in the brain, kidney, heart, small intestine, and liver; and undetectable in the pancreas and in skeletal muscle (Jia et al., 2001). We then assessed the expression pattern of Hic-5 in different regions of the brain by Western blot analysis using a specific polyclonal anti-Hic-5 antibody. As shown in Figure $10 \mathrm{~A}$ (top panel), Hic-5 was expressed in all brain areas examined, with higher levels in the cerebellum, prefrontal cortex, and hypothalamus and lower levels in the thalamus, hippocampus, and striatum. In addition, we observed high levels of Hic-5 protein in spinal cord (Fig. 10A). DAT protein was only detected in the striatum (Fig. 10A, bottom panel), consistent with the high content of this transporter protein in dopaminergic terminals reaching the striatum (Freed et al., 1995).

The association between DAT and Hic-5 in vivo was demonstrated by coimmunoprecipitation experiments using the antiHic-5 antibody. DAT was coprecipitated from striatal tissue extracts but not from the cerebellum (where DAT is not expressed) or muscle (where neither DAT nor Hic-5 is expressed) (Fig. 10B). No interaction between DAT and Hic-5 was detected when an irrelevant antibody was used in the immunoprecipitation (Fig. $10 B$, inset). Together, our findings demonstrate that the adaptor protein Hic-5 exists in dopamine neurons, where it forms a protein complex with DAT.

\section{DISCUSSION}

In this study, we demonstrate that the dopamine transporter interacts in vitro and in vivo with the multiple LIM domaincontaining protein Hic-5, a member of the focal adhesion family of adaptor proteins. This interaction is mediated by the aminoproximal portion of the intracellular $\mathrm{C}$ terminus of DAT and the multiple LIM domain region of Hic-5. DAT and Hic-5 coimmunoprecipitate from brain striatal lysates and synaptically colocalize in midbrain dopaminergic neurons in culture. Hic-5 also interacts with the C termini of NET and to a lesser extent with that of SERT, suggesting that similar interactions might operate in the regulation of other monoamine transporters.

\section{Localization of Hic-5 in central neurons}

Hic-5 was first identified as a transforming growth factor- $\beta 1$ inducible gene in a mouse osteoblastic cell line (Shibanuma et al., 

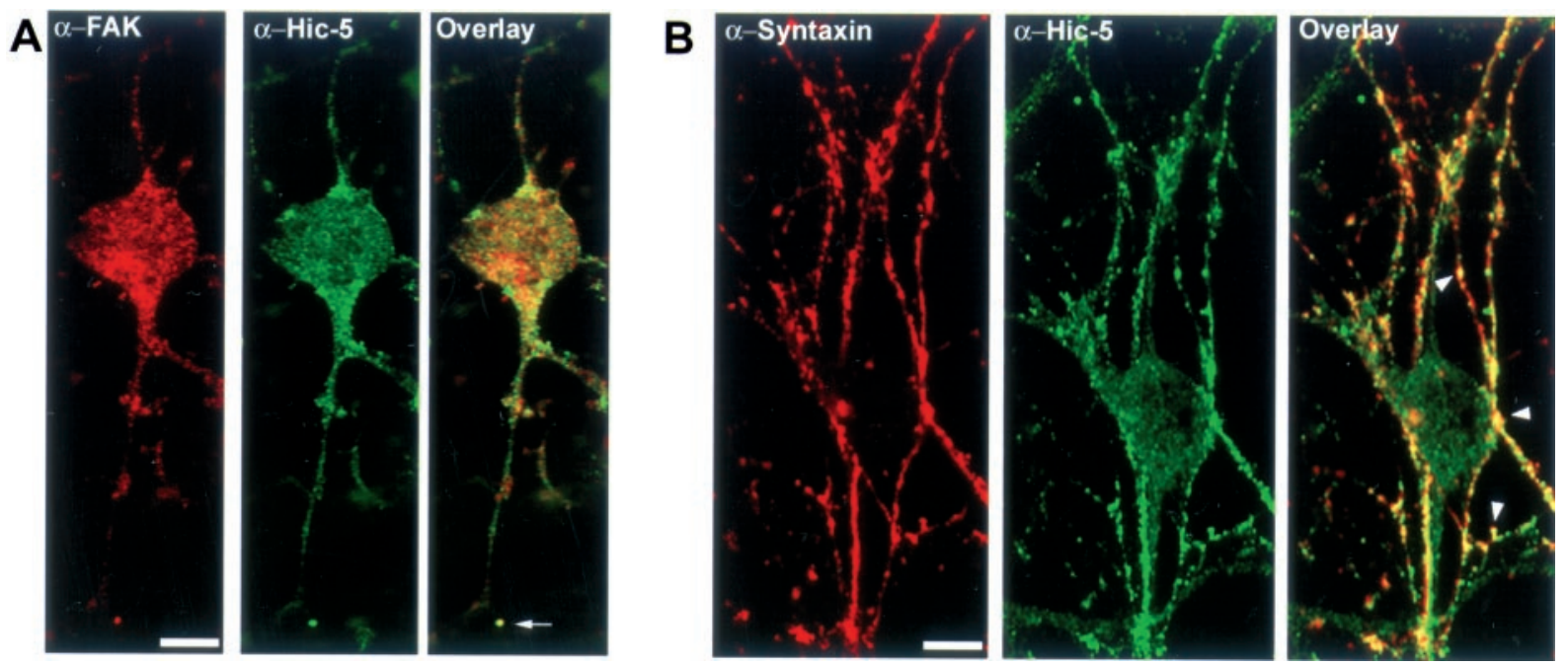

Figure 8. Localization of Hic-5 in rat midbrain culture neurons. A, Neuronal cultures were stained with the rabbit anti-Hic-5 (green) and monoclonal anti-FAK (red) antibodies. FAK and Hic-5 proteins colocalized at the cell bodies and tips of neurites (arrow). B, Neuronal cultures were stained with the anti-Hic-5 (green) and monoclonal anti-syntaxin (red) antibodies. Hic-5 and syntaxin colocalize at presynaptic sites (arrowheads). Scale bars, $15 \mu \mathrm{m}$.
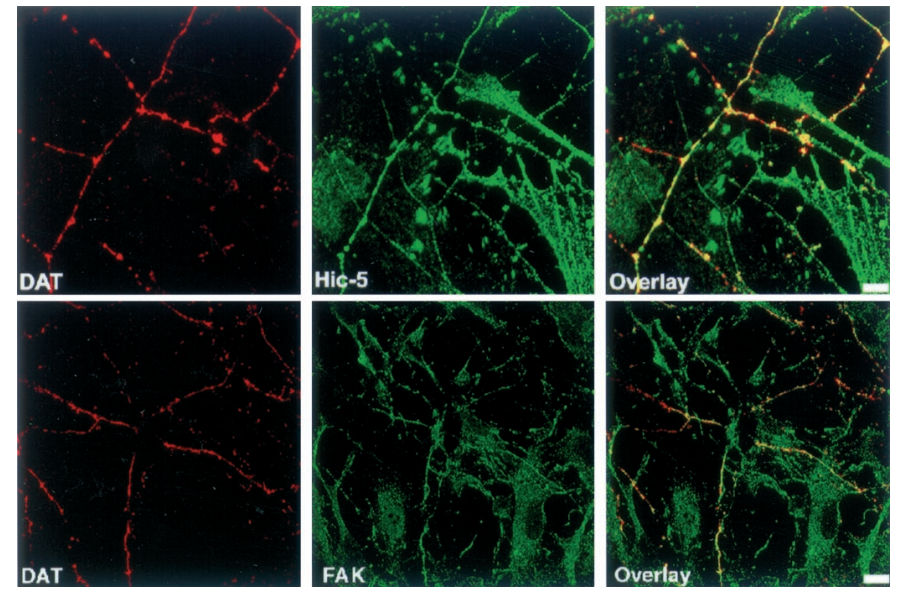

Figure 9. Colocalization of endogenous Hic-5 and DAT in rat dopamine neurons. Double labeling of midbrain primary culture neurons with the anti-Hic-5 (green) and the anti-DAT (red) antibodies is shown. DAT immunoreactivity is observed as clusters along the neurite processes where it colocalizes with Hic-5 (top panels). DAT and FAK are coexpressed in dopamine neurons. Double labeling of midbrain primary culture neurons with anti-FAK ( green) and anti-DAT (red) antibodies is also shown (bottom panels). Scale bars, $10 \mu \mathrm{m}$.

1994). Analysis of the primary sequence of Hic-5 reveals that this protein presents high homology to paxillin, a focal adhesion adaptor protein that regulates integrin- and growth factormediated signaling mechanisms involved in cell motility (Schaller, 2001). In fibroblasts, Hic-5 localizes to focal adhesions and contains protein-protein-interacting domains, including four LIM motifs and four leucine-rich repeats that have been shown to mediate interactions with several signaling molecules, including the nonreceptor tyrosine kinase FAK (Fujita et al., 1998; Hagmann et al., 1998; Thomas et al., 1999; Nishiya et al., 2001), CAK $\beta /$ Pyk2 (Matsuya et al., 1998; Osada et al., 2001), PTPPEST (Nishiya et al., 1999), and the glucocorticoid receptor (Yang et al., 2000). Based on these findings, it has been proposed that Hic-5 regulates focal adhesion dynamics functioning as a scaffolding protein. Although its function is not fully understood, in peripheral cells, Hic-5 might be involved in mechanisms regu-
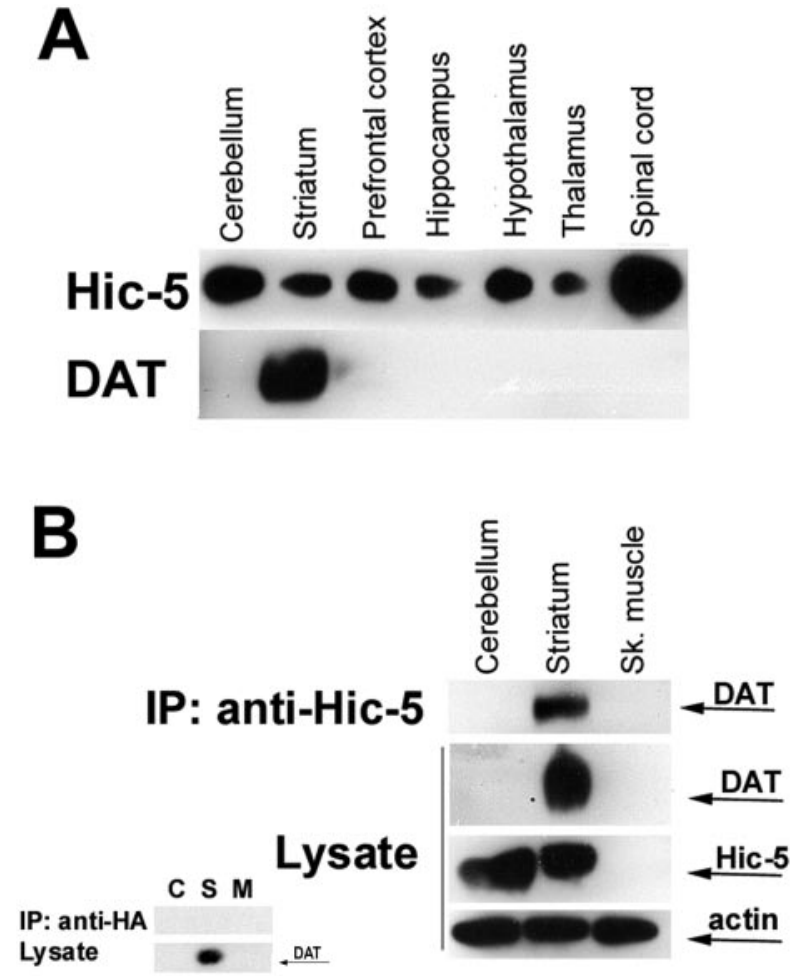

Figure 10. Hic-5 is expressed in several brain areas and forms a protein complex with DAT in the striatum. A, Analysis of Hic-5 and DAT proteins by Western blot in several mouse brain areas and spinal cord. Hic- 5 is expressed in all brain areas examined, whereas DAT protein is detected only in the striatum. $B$, Coimmunoprecipitation of DAT and Hic-5 with the anti-Hic-5 antibody. DAT is coprecipitated by the Hic-5 antibody only in the striatum, where both proteins are expressed, but not in the cerebellum or skeletal muscle (Sk. muscle). DAT is not immunoprecipitated when an irrelevant antibody is used (inset). IP. Immunoprecipitation; $C$, cerebellum; $S$, striatum, $M$, muscle.

lating cell survival, migration, growth, and differentiation (Thomas et al., 1999).

However, despite the attention that Hic-5 has received as a focal adhesion protein in non-neuronal cells, nothing is known 
about the role of this protein in the nervous system. The only available information regarding Hic-5 in the brain comes from the analysis of RNA and protein expression from total brain by Northern and Western blot analysis, respectively (Shibanuma et al., 1994; Jia et al., 2001). In this study, using a specific antibody against Hic-5, we show for the first time the expression of this protein in several brain regions, including the cerebral cortex, hippocampus, hypothalamus, cerebellum, and striatum. In addition, in rat midbrain neurons in culture, Hic-5 shows a punctated localization throughout the neuronal cell body and processes and colocalizes with the focal adhesion protein FAK. These findings represent the first demonstration of the localization of Hic-5 in central neurons and thus suggest a role for this protein in neuronal function.

\section{Molecular mechanism involved in the Hic-5 and DAT interaction}

We have identified a string of residues within amino acids 571 and 580 in the $\mathrm{C}$ terminus of DAT as the main Hic-5-interacting domain. Several residues from this sequence, including Y578, K579, and F580, are conserved in the human NET protein and thus represent putative Hic-5-interacting sites. A detailed mutagenesis study will be necessary to assess the role of these residues in the Hic-5/DAT interaction. Our results also demonstrate that the C-terminal half of Hic-5, which contains the LIM domains, is responsible for the interaction with DAT. In heterologous cells, Hic-5 colocalizes with DAT on one side of the cell and reduces DAT activity by decreasing the cell-surface levels of the transporter. Thus, it appears that Hic-5 recruits DAT to polarized sites in cells, preventing the uniform delivery of transporter proteins to the cell membrane. Alternatively, Hic-5 might increase the turnover of DAT at the cell membrane. Interestingly, a fragment of Hic-5 containing the LIM region prevents the effect of the full-length Hic-5 on DAT localization and function. This fragment binds to DAT but does not inhibit transporter function, indicating that the effect of Hic-5 on DAT function and distribution not only requires interaction with the transporter but also recruitment to polarized sites in cells.

\section{Possible role of the interaction between Hic-5 and DAT}

The synaptic colocalization of Hic-5 and DAT in dopamine neurons in culture as well as the physical association of these two proteins in striatal tissue suggest a role for Hic-5 in DAT function. Hic-5 might act as an adaptor protein, recruiting signaling proteins to macromolecular complexes. In fibroblasts, platelets, and heterologous cells, Hic-5 was shown to interact with the protein tyrosine kinase FAK (Fujita et al., 1998; Hagmann et al., 1998; Thomas et al., 1999; Nishiya et al., 2001). We show here that FAK colocalizes with Hic-5 and with DAT in dopamine neurons. It is tempting to speculate that Hic-5 functions as a scaffolding protein connecting the transporter to intracellular proteins and signal transduction pathways that may include FAK. Interestingly, in mouse striatal synaptosomes and Xenopus oocytes expressing the human DAT, inhibition of protein tyrosine kinases results in a decrease in DAT activity (Simon et al., 1997; Doolen and Zahniser, 2001). These findings were interpreted as a result of a rapid redistribution of transporter molecules from the cell membrane to intracellular compartments (Doolen and Zahniser, 2001). However, the tyrosine kinase(s) involved in the DAT downregulation has not been identified. It is also unknown whether the tyrosine kinase-dependent inhibition of DAT function is caused by direct phosphorylation of the transporter or by an accessory protein involved in trafficking. Thus, FAK might regulate DAT function through a mechanism in which the transporter is associated with the kinase via Hic-5. In support of this hypothesis, we have observed an interaction between Hic-5 and FAK in synaptosomes from mouse striatum (A. Carneiro, unpublished observations). Alternatively, DA or DAT substrates might regulate FAK function through the activation of DAT, suggesting a role for DAT in FAK-mediated signaling mechanisms. Such a mechanism has been proposed for the glutamate ionotropic AMPA receptor. Activation of AMPA receptors with glutamate increases FAK catalytic function in Bergmann glia cells through a mechanism involving an interaction between the AMPA receptor and FAK (Millan et al., 2001). In addition, Hayashi et al. (1999) have recently shown a functional interaction between AMPA receptors and the Src-family nonreceptor protein tyrosine kinase Lyn. Another interesting possibility is the involvement of the protein tyrosine kinase Fyn in DAT regulation, because Fyn was shown recently to phosphorylate Hic-5 (Ishino et al., 2000). Thus, the association of Hic- 5 with DAT might be regulated by tyrosine phosphorylation. Such a mechanism has been shown for NMDA receptors. Kohr and Seeburg (1996) demonstrated that NMDA receptor-associated currents were potentiated in the presence of Fyn.

\section{Protein-protein interactions regulating plasma membrane neurotransmitter transporters}

By regulating the extracellular levels of DA at the synapse, the DAT protein has emerged as an indispensable molecule controlling dopaminergic transmission in the brain. Deletion of the DAT gene in mice results in profound changes in neuronal plasticity, dopamine receptor responsiveness, sensitivity to psychostimulants, and locomotor activity (Gainetdinov et al., 1999). However, little is known about the molecular mechanisms and the protein interactions that regulate DAT expression and function. For other neurotransmitter transporters, recent evidence supports the involvement of interacting proteins in the regulation of transporter function. The neuronal glutamate transporters excitatory amino acid carrier-1 and excitatory amino acid transporter-4 (EAAT4) were shown to interact with a novel family of interacting proteins termed glutamate transporter associated proteins (GTRAPs) (Jackson et al., 2001; Lin et al., 2001). GTRAP41 and GTRAP48 increase the activity of EAAT4 by a mechanism involving an increase in the cell-surface transporter molecules, suggesting that these interactions may modulate the synaptic localization of EAAT4 (Jackson et al., 2001). In the case of GABA and glycine transporters, an interaction with syntaxin, plasma membrane proteins associated with the synaptic vesicle release machinery, has also been demonstrated (Beckman et al., 1998; Geerlings et al., 2001; Horton et al., 2001). Syntaxin binding to GABA and glycine transporters appears to regulate their redistribution to and from the cell membrane. We have identified previously an interaction between DAT and the PDZ domaincontaining protein PICK1 (Torres et al., 2001). This association involves the PDZ domain of PICK1 and the last three residues of the transporter. The PICK1 binding site in DAT is essential for the proper targeting of the transporter to neuronal processes, indicating that a specific protein-protein interaction appears to regulate the localization of DAT in neurons. In addition, synuclein, a presynaptic protein implicated in the expression of some forms of Parkinson's disease, also binds DAT and regulates the membrane expression of the transporter (Lee et al., 2001). The results presented here provide evidence for the association of 
the adaptor protein Hic-5 with DAT. Such interaction could serve to regulate DAT integrity and/or location, in addition to modulating transporter properties.

It becomes evident that protein-protein interactions play a major role in the function of DAT at least at three different levels. First, protein-protein interactions must be required during the early stages of the cell biology of DAT (i.e., synthesis, assembly, and trafficking of the transporter through intracellular membranes). Second, the specific targeting of DAT to perisynaptic membranes of nerve terminals also suggests that specific proteinprotein interactions must contain localization signals that target the transporter to specialized membrane compartments. We have shown previously that the interaction of DAT with PICK1 appears to regulate the localization of the transporter in neurons. Third, activation of several second-messenger systems affects the trafficking of DAT to and from the cell membrane. In DATexpressing cells treated with phorbol esters or protein tyrosine kinase inhibitors, transporters are rapidly redistributed from the cell surface to intracellular compartments (Zahniser and Doolen, 2001). Thus, transporter-associated proteins must participate in the internalization and/or recycling of DAT from or to the cell surface.

The regulation of DAT in neurons may be far more complex than anticipated. Given the significance of DAT in normal and abnormal brain function, the identification of interacting proteins provides new opportunities to dissect the accessory components involved in transporter function and regulation. Our data suggest that Hic-5, a multiple LIM domain-containing protein, associates with DAT and may function as an adaptor protein that links the transporter to a macromolecular signaling complex. Future studies should be aimed at examining the physiological implications of this linkage.

\section{REFERENCES}

Amara SG, Sonders MS (1998) Neurotransmitter transporters as molecular targets for addictive drugs. Drug Alcohol Depend 51:87-96.

Bannon MJ, Sacchetti P, Granneman JG (1998) The dopamine transporter: potential involvement in neuropsychiatric disorders. In: Psychopharmacology: the fourth generation of progress (Watson SJ, ed), pp 3-7. Philadelphia: Lippincott Williams \& Wilkins.

Beckman ML, Bernstein EM, Quick MW (1998) Protein kinase C regulates the interaction between a GABA transporter and syntaxin $1 \mathrm{~A}$. J Neurosci 18:6103-6112.

Blakely RD, Ramamoorthy S, Schroeter S, Qian Y, Apparsundaram S, Galli A, DeFelice LJ (1998) Regulated phosphorylation and trafficking of antidepressant-sensitive serotonin transporter proteins. Biol Psychiatry 44:169-178.

Daniels GM, Amara SG (1999) Regulated trafficking of the human dopamine transporter. Clathrin-mediated internalization and lysosomal degradation in response to phorbol esters. J Biol Chem 274:3579435801.

Doolen S, Zahniser NR (2001) Protein tyrosine kinase inhibitors alter human dopamine transporter activity in Xenopus oocytes. J Pharmacol Exp Ther 296:931-938.

Freed C, Revay R, Vaughan RA, Kriek E, Grant S, Uhl GR, Kuhar MJ (1995) Dopamine transporter immunoreactivity in rat brain. J Comp Neurol 359:340-349.

Fujita H, Kamiguchi K, Cho D, Shibanuma M, Morimoto C, Tachibana K (1998) Interaction of Hic-5, a senescence-related protein, with focal adhesion kinase. J Biol Chem 273:26516-26521.

Gainetdinov RR, Jones SR, Caron MG (1999) Functional hyperdopaminergia in dopamine transporter knock-out mice. Biol Psychiatry 46:303-311.

Geerlings A, Nunez E, Lopez-Corcuera B, Aragon C (2001) Calciumand syntaxin 1-mediated trafficking of the neuronal glycine transporter GLYT2. J Biol Chem 276:17584-17590.

Giros B, Caron MG (1993) Molecular characterization of the dopamine transporter. Trends Pharmacol Sci 14:43-49.

Giros B, el Mestikawy S, Bertrand L, Caron MG (1991) Cloning and functional characterization of a cocaine-sensitive dopamine transporter. FEBS Lett 295:149-154.

Giros B, Wang YM, Suter S, McLeskey SB, Pifl C, Caron MG (1994)
Delineation of discrete domains for substrate, cocaine, and tricyclic antidepressant interactions using chimeric dopamine-norepinephrine transporters. J Biol Chem 269:15985-15988.

Giros B, Jaber M, Jones SR, Wightman RM, Caron MG (1996) Hyperlocomotion and indifference to cocaine and amphetamine in mice lacking the dopamine transporter. Nature 379:606-612.

Hagmann J, Grob M, Welman A, van Willigen G, Burger MM (1998) Recruitment of the LIM protein hic-5 to focal contacts of human platelets. J Cell Sci 111:2181-2188.

Hayashi T, Umemori H, Mishina M, Yamamoto T (1999) The AMPA receptor interacts with and signals through the protein tyrosine kinase Lyn. Nature 397:72-76.

Hepp R, Langley K (2001) SNAREs during development. Cell Tissue Res 305:247-253.

Horton N, Quick MW (2001) Syntaxin 1A up-regulates GABA transporter expression by subcellular redistribution. Mol Membr Biol 18:39-44.

Ishino M, Aoto H, Sasaski H, Suzuki R, Sasaki T (2000) Phosphorylation of Hic-5 at tyrosine 60 by CAKbeta and Fyn. FEBS Lett 474:179-183

Jackson M, Song W, Liu MY, Jin L, Dykes-Hoberg M, Lin CI, Bowers WJ, Federoff HJ, Sternweis PC, Rothstein JD (2001) Modulation of the neuronal glutamate transporter EAAT4 by two interacting proteins. Nature 410:89-93.

Jia Y, Ransom RF, Shibanuma M, Liu C, Welsh MJ, Smoyer WE (2001) Identification and characterization of hic-5/AR A55 as an hsp27 binding protein. J Biol Chem 276:39911-39918.

Jones SR, Gainetdinov RR, Jaber M, Giros B, Wightman RM, Caron MG (1998) Profound neuronal plasticity in response to inactivation of the dopamine transporter. Proc Natl Acad Sci USA 95:4029-4034.

Kilty JE, Lorang D, Amara SG (1991) Cloning and expression of a cocaine-sensitive rat dopamine transporter. Science 254:578-579.

Kohr G, Seeburg PH (1996) Subtype-specific regulation of recombinant NMDA receptor-channels by protein tyrosine kinases of the src family. J Physiol (Lond) 492:445-452.

Lee FJ, Liu F, Pristupa ZB, Niznik HB (2001) Direct binding and functional coupling of alpha-synuclein to the dopamine transporters accelerate dopamine-induced apoptosis. FASEB J 15:916-926.

Lin CI, Orlov I, Ruggiero AM, Dykes-Hoberg M, Lee A, Jackson M, Rothstein JD (2001) Modulation of the neuronal glutamate transporter EAAC1 by the interacting protein GTRAP3-18. Nature 410:84-88.

Masson J, Sagne C, Hamon M, El Mestikawy S (1999) Neurotransmitter transporters in the central nervous system. Pharmacol Rev 51:439-464.

Matsuya M, Sasaki H, Aoto H, Mitaka T, Nagura K, Ohba T, Ishino M, Takahashi S, Suzuki R, Sasaki T (1998) Cell adhesion kinase beta forms a complex with a new member, Hic-5, of proteins localized at focal adhesions. J Biol Chem 273:1003-1014.

Melikian HE, Buckley KM (1999) Membrane trafficking regulates the activity of the human dopamine transporter. J Neurosci 19:7699-7710.

Millan A, Aguilar P, Mendez JA, Arias-Montano JA, Ortega A (2001) Glutamate activates PP125(FAK) through AMPA/kainate receptors in Bergmann glia. J Neurosci Res 66:723-729.

Nishiya N, Iwabuchi Y, Shibanuma M, Cote JF, Tremblay ML, Nose K (1999) Hic-5, a paxillin homologue, binds to the protein-tyrosine phosphatase PEST (PTP-PEST) through its LIM 3 domain. J Biol Chem 274:9847-9853.

Nishiya N, Tachibana K, Shibanuma M, Mashimo JI, Nose K (2001) Hic-5-reduced cell spreading on fibronectin: competitive effects between paxillin and Hic-5 through interaction with focal adhesion kinase. Mol Cell Biol 21:5332-5345.

Osada M, Ohmori T, Yatomi Y, Satoh K, Hosogaya S, Ozaki Y (2001) Involvement of Hic-5 in platelet activation: integrin alphaIIbbeta3dependent tyrosine phosphorylation and association with proline-rich tyrosine kinase 2. Biochem J 355:691-697.

Parsons JT, Martin KH, Slack JK, Taylor JM, Weed SA (2000) Focal adhesion kinase: a regulator of focal adhesion dynamics and cell movement. Oncogene 19:5606-5613.

Pristupa ZB, McConkey F, Liu F, Man HY, Lee FJ, Wang YT, Niznik HB (1998) Protein kinase-mediated bidirectional trafficking and functional regulation of the human dopamine transporter. Synapse 30:79-87.

Rayport S, Sulzer D, Shi WX, Sawasdikosol S, Monaco J, Batson D, Rajendran G (1992) Identified postnatal mesolimbic dopamine neurons in culture: morphology and electrophysiology. J Neurosci $12: 4264-4280$.

Schaller MD (2001) Paxillin: a focal adhesion-associated adapter protein. Oncogene 20:6459-6472.

Sealfon SC, Olanow CW (2000) Dopamine receptors: from structure to behavior. Trends Neurosci 23:34-40.

Shibanuma M, Mashimo J, Kuroki T, Nose K (1994) Characterization of the TGF beta 1-inducible hic-5 gene that encodes a putative novel zinc finger protein and its possible involvement in cellular senescence. J Biol Chem 269:26767-26774. 
Shibanuma M, Mochizuki E, Maniwa R, Mashimo J, Nishiya N, Imai S, Takano T, Oshimura M, Nose K (1997) Induction of senescence-like phenotypes by forced expression of hic-5, which encodes a novel LIM motif protein, in immortalized human fibroblasts. Mol Cell Biol 17: $1224-1235$.

Shimada S, Kitayama S, Lin CL, Patel A, Nanthakumar E, Gregor P, Kuhar M, Uhl G (1991) Cloning and expression of a cocaine-sensitive dopamine transporter complementary DNA. Science 254:576-578.

Simon JR, Bare DJ, Ghetti B, Richter JA (1997) A possible role for tyrosine kinases in the regulation of the neuronal dopamine transporter in mouse striatum. Neurosci Lett 224:201-205.

Thomas SM, Hagel M, Turner CE (1999) Characterization of a focal adhesion protein, Hic-5, that shares extensive homology with paxillin. J Cell Sci 112:181-190.
Torres GE, Yao WD, Mohn AR, Quan H, Kim KM, Levey AI, Staudinger J, Caron MG (2001) Functional interaction between monoamine plasma membrane transporters and the synaptic PDZ domain-containing protein PICK1. Neuron 30:121-134.

Yang L, Guerrero J, Hong H, DeFranco DB, Stallcup MR (2000) Interaction of the tau2 transcriptional activation domain of glucocorticoid receptor with a novel steroid receptor coactivator, Hic-5, which localizes to both focal adhesions and the nuclear matrix. Mol Biol Cell 11:2007-2018.

Zahniser NR, Doolen S (2001) Chronic and acute regulation of $\mathrm{Na}+$ / $\mathrm{Cl}$--dependent neurotransmitter transporters: drugs, substrates, presynaptic receptors, and signaling systems. Pharmacol Ther 92: $21-55$. 